\title{
Built Environment andActive Transport to School (BEATS) Study: Multidisciplinary and Multi-Sector Collaboration for Physical Activity Promotion El estudio «Entorno construido y desplazamiento activo a la escuela (BEATS)»: colaboración multidisciplinaria y multisectorial para la promoción de la actividad física Sandra Mandic*, Ashley Mountfort*, Debbie Hopkins*, Charlotte Flaherty**, John Williams*, Emily Brook*, Gordon Wilson***, Antoni Moore* \\ *University of Otago, Dunedin, New Zealand, **Dunedin City Council, Dunedin, New Zealand, ***Dunedin Secondary Schools’ Partnership, Dunedin, New Zealand
}

\begin{abstract}
The Built Environment and Active Transport to School (BEATS) Study examines active transport to school (ATS) in adolescents in Dunedin, New Zealand, using the ecological model for active transport which accounts for individual, social, environmental, and policy influences. This article describes the BEATS Study design, the establishment of research and community collaborations, planning and preparation for data collection, study implementation and dissemination activities and selected preliminary findings. The BEATS Study is founded on a multidisciplinary approach and multi-sector collaborations between secondary schools, the city council, the local communities, and academia. The study uses a mixed-method approach incorporating both quantitative (survey) and qualitative (focus groups/interviews) approaches with students, parents, teachers and school principals. All 12 secondary schools in Dunedin, New Zealand, are participating in the study. As of September 2014, 1,272 adolescents from nine schools (age: $15.3 \pm 1.4$ years; $46.6 \%$ boys) completed the student survey. Three additional schools will be surveyed in 2015 . On average, $33.0 \%$ of Dunedin adolescents use ATS. ATS rates vary greatly by school (range: $8.6 \%$ to $46.5 \%$ ) and most students like the way how they travel to school (88.3\%). With $100 \%$ school recruitment rate, this study provides a unique sample of students and parents across one city with a heterogeneous physical environment. The findings will enable community health promoters, policy makers and city planners to address ATS barriers, encourage active transport and create supportive built environments to promote ATS.
\end{abstract}

Keywords: Active transport, adolescents, built environment, physical activity.

Resumen. El estudio de entornos construidos y transporte activo a la escuela examina el transporte activo a la escuela (TAE) en adolescentes en Dunedin, Nueva Zelanda, utilizando el modelo ecológico para representar las influencias individuales, sociales, ambientales y de políticas que tienen relación con el transporte activo. En este artículo se describe el diseño del Estudio BEATS, el establecimiento de la investigación y las colaboraciones con la comunidad, la planificación y la preparación para la recopilación de datos, la implementación del estudio y las actividades de difusión, y una selección de las conclusiones preliminares. El Estudio BEATS se basa en un enfoque multidisciplinar y en colaboraciones multisectoriales entre los colegios de Secundaria, el consejo de gobierno la ciudad, las comunidades locales y el ámbito académico. El estudio utiliza métodos mixtos incorporando tanto técnicas cuantitativas (encuesta) como cualitativas (grupos focales / entrevistas) con los estudiantes, padres, maestros y directores de los centros escolares. Los 12 colegios de Educación Secundaria en Dunedin, Nueva Zelanda, están participando en el estudio. En septiembre de 2014, 1.272 adolescentes de nueve centros (edad: 15,3 \pm 1,4 años; 46,6\% varones) completaron la encuesta estudiantil. Tres escuelas adicionales serán encuestadas en 2015. En promedio, el 33,0\% de los adolescentes en Dunedin usan TAE. Las tasas de TAE varían en gran medida en función del colegio (rango: 8,6\% a 46,5\%) y a la mayoría de los estudiantes les gusta la forma en que se desplazan al centro escolar (88,3\%). Con el 100\% de tasa de reclutamiento de colegios, este estudio ofrece una muestra única de los estudiantes y padres de una ciudad con un entorno físico heterogéneo. Los resultados permitirán a los promotores de salud comunitarios, políticos y diseñadores urbanos hacer frente a las barreras relativas al TAE, fomentar el transporte activo y crear entornos construidos facilitadores para promover el TAE.

Palabras clave: transporte activo, adolescentes, entorno construido, actividad física.

\section{Introduction}

Physical inactivity and sedentary lifestyles among adolescents are global public health problems. Active transport to school (ATS), such as walking, cycling or riding a scooter, is a convenient way to maintain or increase physical activity levels (Faulkner, Buliung, Flora, \& Fusco, 2009; Mendoza et al., 2011) and, in the long term, will contribute to improving health and wellbeing of adolescents. However, despite great variations in the prevalence of ATS between countries (Guthold, Cowan, Autenrieth, Kann, \& Riley, 2010), international data suggest a consistent decline in ATS among adolescents over the last decade (Chillón et al., 2012; McDonald, 2007; Ministry of Transport, 2011). Previous research showed that ATS in adolescents is influenced by a number of factors including individual demographic factors (age (Pabayo, Gauvin, \& Barnett, 2011), gender (Babey, Hastert, Huang, \& Brown, 2009; Larsen et al., 2009)), family factors (socio-economic status (Babey et al., 2009; McDonald, 2008), number vehicles at home (McDonald, 2008)), social factors (encouragement from peers and parents; peers using ATS), environmental factors (distance to school (Babey et al., 2009; Larsen et al., 2009; McDonald, 2008), built environment characteristics (Larsen et al., 2009; Panter, Jones, Van Sluijs, \& Griffin, 2010; Timperio et al., 2006); topography (Timperio et al., 2006)), safety concern (parental safety concerns (Carver, 2010)) and policy factors (availability of bike racks at school; school uniform policy).

Fecha recepción: 30-09-14- Fecha envío revisores: 30-09-14- Fecha de aceptación: 15-11-14 Sandra Mandic

sandra.mandic@otago.ac.nz
Most previous studies have been conducted on adolescents in urban areas of the United States (Babey et al., 2009; Kerr et al., 2006), Canada (Larsen et al., 2009), Australia (Timperio et al., 2006) and Western Europe (Bringolf-Isler et al., 2008; Panter et al., 2010), which have different urban layouts and social norms compared to New Zealand. In particular, New Zealand has one of the highest rates of private vehicle ownership per capita in the world (The World Bank, 2014). Understanding factors that influence adolescents' transport to school choices in a local context will enable scientific community, policy makers, city planners, and health promoters to address ATS barriers, create supportive environments for encouraging ATS and reduce the reliance on motorised transport in this age group.

The Otago School Students Lifestyle Surveys (2009, 2011) examined physical activity and dietary habits in 2,798 New Zealand adolescents (Howe, Mandic, Parnell, \& Skidmore, 2013; Mandic, García Bengoechea, Stevens, Leon de la Barra, \& Skidmore, 2012). The results showed that walking was the most common form of ATS, that commuting distance was one of the strongest multivariate correlates of ATS (Mandic et al., 2014) and that transport to school habits are influenced by objective measures of the built environment (Moore, Middlemiss, Hodge, Skidmore, \& Mandic, 2013). In a multivariate analysis, shorter distance to school, younger age, fewer vehicles and fewer screens per household, meeting screen time guidelines, attractive surroundings, parental perceptions of ATS safety and students' perceptions of ATS as an opportunity to chat with friends were positively associated with active transport to school. Perceived time constraints and attending girls-only school had a negative association with active transport to school (Mandic et al., 2014). These results from the Otago School 
Students Lifestyle Survey as well as established collaborative networks between academia, local city council and schools informed the design of the Built Environment and Active Transport to School: The BEATS Study in 2013.

\section{The BEATS Study}

Conceptual framework and purpose. The BEATS Study is based on the most contemporary ecological model for active transport (Sallis et al., 2006) which accounts for individual, social, environmental, and policy influences. The purpose of the BEATS Study is three-fold: 1) to understand the reasons behind adolescents' and their parents' choice of transport mode to school using the ecological approach; 2) to examine the interaction between the transport choices, built environment, physical activity levels, and weight status in adolescents; and 3) to identify policies that promote or limit ATS in adolescents. The results of the BEATS Study will inform health promotion efforts and shape future interventions and policies to promote ATS in adolescents.

Study overview. The BEATS Study uses a mixed-method approach incorporating both quantitative (questionnaires and physical measurements) and qualitative (focus groups and interviews) methods to gather data from students, parents, teachers, and school principals. The core data include objective measures of moderate-to-vigorous physical activity (measured using accelerometers), anthropometry, the built environment (derived through Geographic Information System [GIS] analytical techniques) and the use of maps to collect data about perceived safe or unsafe areas on adolescents' route to school. The study consists of six different sub-projects: 1) student survey, 2) student focus groups, 3) parental survey; 4) parental focus groups, 5) teachers focus groups and 6) school principal interviews.

\section{The BEATS Study Collaborations}

Multidisciplinary and multi-sectoral collaborations. The BEATS Study is founded on a multidisciplinary approach and multisectoral collaborations between secondary schools, city council, community, and academia (Figure 1). The BEATS Research Team is multidisciplinary with expertise ranging from exercise science, behavioural medicine, and health promotion to geographic information science, statistics, consumer behaviour and environmental sociology, and involves international research collaborations. In addition to academics, theresearch team has representatives from Dunedin Secondary Schools' Partnership, Dunedin City Council and Getting Dunedin Active Initiative. The research team also obtained further academic support from colleagues at the University of Otago with expertise in conducting large multidisciplinary research projects, focus group research and working with adolescents. These individuals formed theAdvisory Board for the BEATS Study.

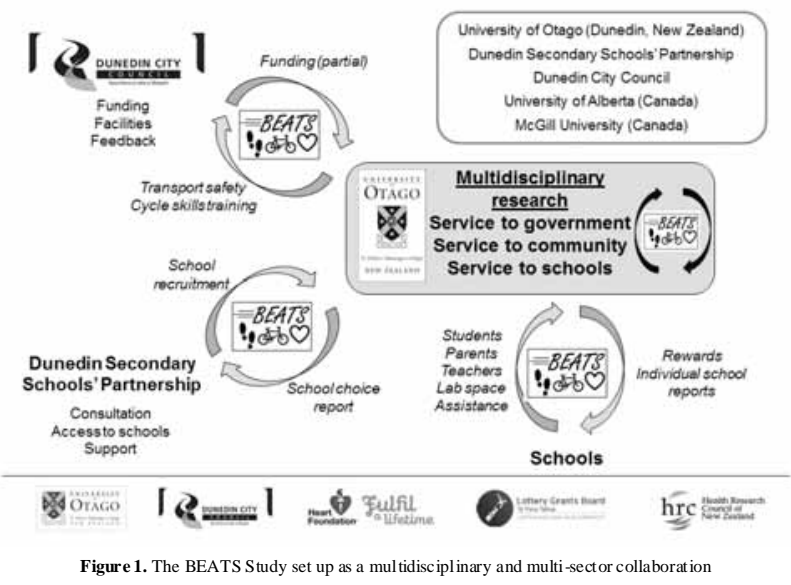

Building Links with the Community. The BEATS Research Team has established strong links with and obtained support from the secondary schools, local authority and physical activity sector of the Dunedin community. As described above, the BEATS Study has been designed as a collaborative project involving the University of Otago, the Dunedin Secondary Schools' Partnership and the Dunedin City Council. A key aspect of this collaboration was the involvement of the Dunedin Secondary Schools' Partnership and the Dunedin City Council from the inception phase as well as the incorporation of their input into the study design. This early involvement of stakeholders from multiple sectors provided comprehensive input into the study design and ensured their buy-in and support for the implementation phase of the project. Timelines for the BEATS Study design and establishing collaborations, planning and preparation, implementation and dissemination are presented in Figure 2.

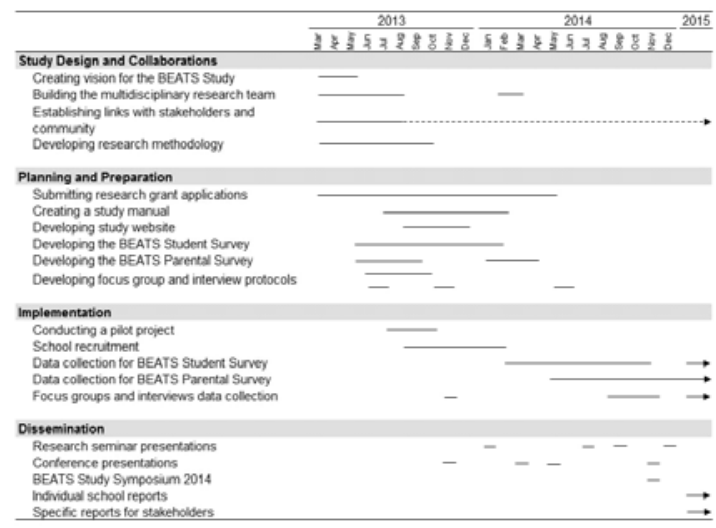

Figure 2. The BEATS Study Timeline for study design and establishing coll aborations, planning and preparation, implementation and dissemination activities

Providing Service to the Community. Another essential aspect in the establishment of strong links with the community was designing a research study that will also provide service to the community, Dunedin secondary schools and the local city council. In addition to research outputs, the BEATS Study has been designed to provide timely, valuable and comprehensive information to the participating organizations on relevant issues related to school choice, transport to school and safety around Dunedin secondary schools. For example, as a part of the BEATS Study, participating schools are gaining comprehensive information about the reasons why adolescents and/or their parents are choosing a particular school. This information will be essential to understand adolescents' needs and preferences, to anticipate future trends in school enrolment, to inform schools' marketing campaigns and to anticipate needs for future resource allocation that will meet the demands of individual schools. In addition, the BEATS Study will provide the local city council with comprehensive baseline data to evaluate the effect of major cycling infrastructure changes on adolescent transport behaviour and will inform discussions on how to best meet transportation needs of adolescents in the city. More specifically, the BEATS Study has been designed to provide comprehensive baseline data for a future natural experiment that will examine the impact of changes in the built environment (South Dunedin Cycle Network; developments 2013-2015) on cycling to school habits and the perceptions of cycling in Dunedin adolescents. Moreover, the results of the study will inform the design of a proposed school-based initiative (cycle skills training in Dunedin secondary schools, 2015-onwards) and a neighbourhood-based intervention (calendar of cycling events and bike library in South Dunedin; 2015-onwards) to promote cycling in Dunedin. The New Zealand Transport Agency is also interested in the study findings with respect to the international and national trends in changing driving behaviours in adolescents. Taken together, these findings will provide important information for designing future school-, neighbourhood-and city-wide interventions to encourage active transport among adolescents as a means of increasing physical activity in this age group. The establishment of close links with the Dunedin community and the resulting provision of the service to the community, led to the BEATS Study being supported by the Dunedin Secondary Schools' 
Partnership and identified as a priority research project in Dunedin secondary schools in 2014-2015. In addition, the BEATS Study has been included as one of the key projects in the strategic plan 2014/15 of the Getting Dunedin Active Initiative (a multi-sector partnership of health promoting organizations in the city of Dunedin).

\section{Planning and Preparation}

Obtaining Funding. Applications for research grants started at the inception of the study (March 2013). Obtaining a small internal research grant for conducting the pilot project for the BEATS Student Survey in 2013 was an essential step before further funding was obtained from Dunedin City Council in 2013 (two equipment grants for purchasing accelerometers). This initial funding and conducting a pilot project in 2013 were instrumental in attracting larger external research funding and university research grants later on.

Study Website. The BEATS Study website (www.otago.ac.nz/ beats) was set up in late 2013 to provide information about the study to the schools and replace paper-based school manuals that our research team used in previous similar projects. The website has been used extensively to promote the BEATS Study in the community, provide detailed information about the study for schools, study participants, policy makers and researchers, inform stakeholders about progress and offer information about events organized by the BEATS Research Team such as the BEATS Study Symposium, which was held in November 2014

Preparation for Data Collection. An outline of preparation for data collection for the BEATS Study is shown in Figure 3. The preparation started with the development of study questionnaires over 10 months for the student survey and nine months for the parental survey. Question guides were developed for focus groups (student, parental, and teachers) and interviews (school principals) building upon the aims for each sub-project. The focus group questions were specific to the particular group, whilst also allowing for cross-group comparisons. Another key task was the development of the study materials including study pamphlets, study website (described above), study posters and advertisements. As a part of this process, we developed a research study manual that included a project summary, standard operating procedures, project timelines, processes for working with each individual school and relevant contact details. The research manual was extensively used by the research team members during the data collection phase of the study for training new research staff and finding projectrelevant information in one document.

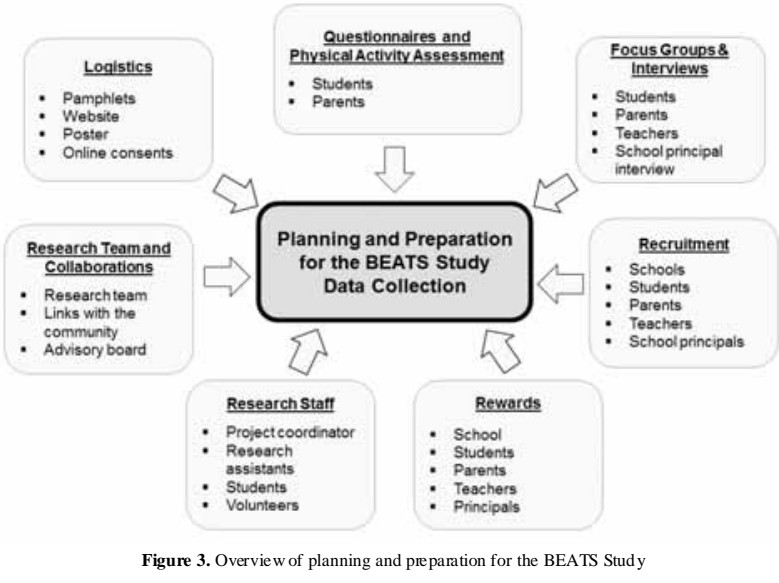

\section{Implementation}

BEATS Pilot Project. In August-September 2013, a pilot project was conducted in four Dunedin secondary schools and included surveying 160 students. This project was used to pilot test the student survey and data collection procedures. The pilot project provided essential information for finalizing the student survey and revising data collection procedures for the main study in 2014-2015.

Recruiting Schools. Schools were recruited with the assistance of the Dunedin Secondary Schools' Partnership. The investigators were invited to present the BEATS Study proposal to school principals in August 2013. In October-December 2013, the investigators met individually with the school principals and discussed the details of conducting the BEATS Study in each school. By February 2014 The study received a $100 \%$ school recruitment rate with all 12 secondary schools in Dunedin agreeing to participate in the BEATS Study. This is one of the key strengths of this study, and to our knowledge is very rare in studies examining factors that influence ATS.

Recruiting and Training Research Staff. Recruitment and training of the study coordinator at an early stage of the project development was essential for an adequate preparation for the data collection phase. Additional research staff included three part-time research assistants, nine research assistants available on as-needed basis for data collection at schools, students and volunteers. The training of the new research staff members was organized by the study coordinator and included training in standard operating procedures, anthropometry measurements and initializing and downloading accelerometer data. In addition, our research team organized monthly research seminars for research assistants, students and volunteers on topics ranging from literature review and data analysis to abstract writing and preparing conference presentations.

Data collection. Management of the BEATS Study data collection was a complex task and required extensive communications with the participating schools and study participants as well as within the BEATS Research Team. To facilitate coordination of the multiple data collection tasks for the BEATS Study, we created a detailed work breakdown structure for relevant tasks to be completed in each individual school (Figure 4) and a similar work breakdown structure for the BEATS Student Survey data collection. These documents were essential in the management of the data collection process for the BEATS Study.

Data Collection for the BEATS Student Survey. Participating adolescents completed the BEATS Student Survey during one class period of 50 to 60 minutes. All participating adolescents signed consent for taking part in the study. For adolescents under 16 years of age, parents signed either parental opt-out or parental opt-in consent based on the school's preference. The study was approved by the University of Otago Ethics Committee.

During the class, adolescents completed an anonymous online questionnaire (30 to 40 minutes), anthropometry measurements in the screened off area of the class, and a map indicating their route to school. The BEATS Student questionnaire included sections on demographics, school choice, transport to school habits, attitudes towards walking and cycling to school, the Neighbourhood Environment Walkability Scale For Adolescents (Kerr et al., 2006), health behaviours, mobile phone use and perceptions of driving and learning to drive. Adolescents' height, weight and waist circumference were measured using a portable stadiometer and weight scale, respectively. After completion of the online questionnaire, adolescents completed the map indicating the usual mode of transport to school, their route to school and any areas along the route that they felt were unsafe. Three to six research staff and a teacher were present in the classroom. Researchers monitored students as they were completing the online questionnaire, which is a strength of this study. As a result, a very small number of survey responses were marked as invalid. However the vast majority of students completed the survey task conscientiously, often putting a lot of thought into their responses.

Adolescents were also given an opportunity to participate in the objective measurement of physical activity using accelerometers. Adolescents received their accelerometer at the school within one to three weeks after the survey and were asked to wear it for seven consecutive days. Adolescents returned their accelerometer to the school and were offered book vouchers rewards for both wearing the 


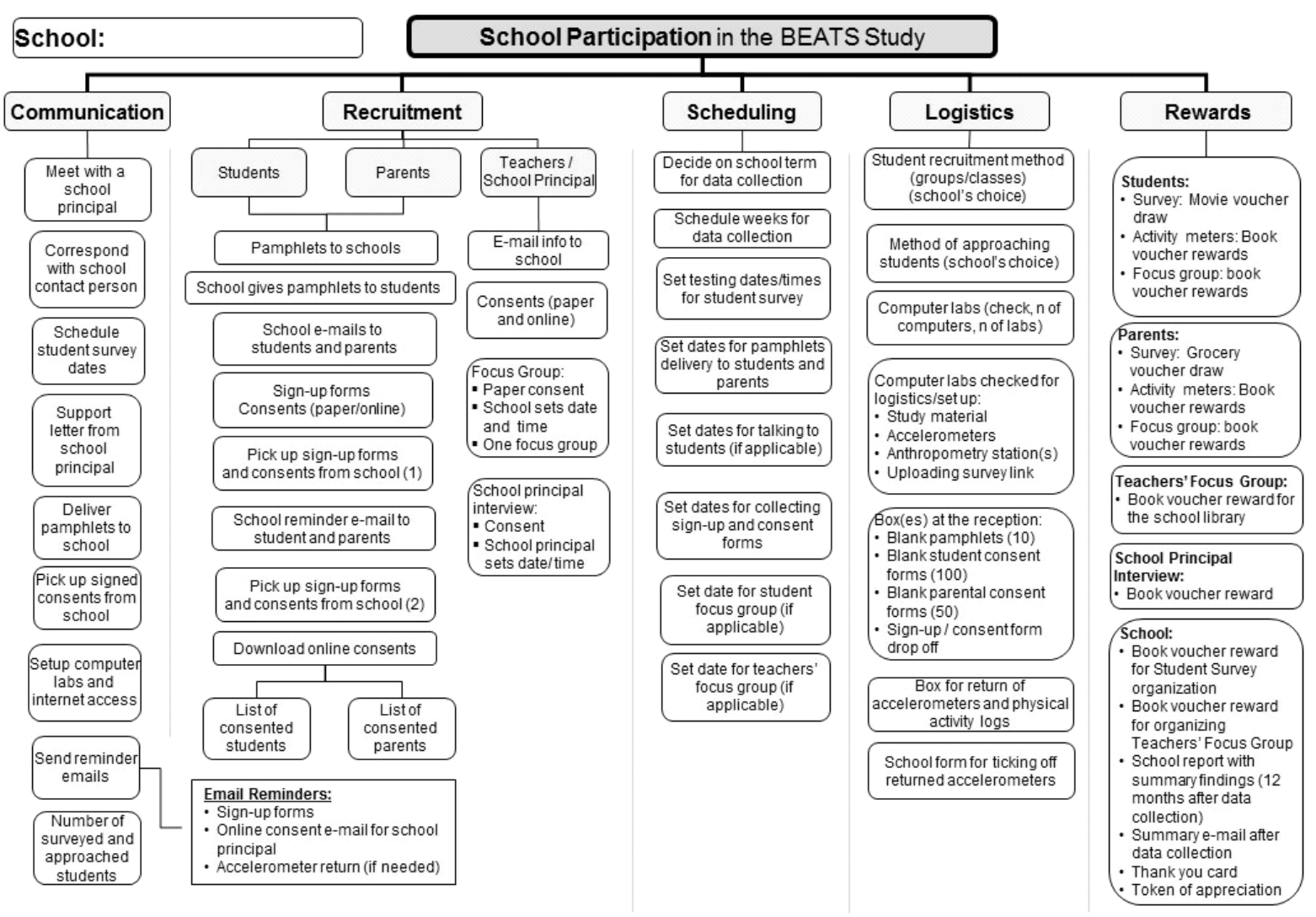

Figure 4. Work breakdown stucture for BEATS Study planning in each participating school

accelerometer for seven day and/or returning it to the school on a scheduled date. Further data generated from the BEATS Student Survey will include objective measures of the built environment derived through Geographic Information System [GIS] analytical techniques.

Tracking progress. To track progress of the data collection for the BEATS Student Survey, our research team devoted time to preparing monthly recruitment reports that were discussed at the monthly meetings of the BEATS research team. In addition, our research team put an extra effort to create regular progress reports for individual schools to keep

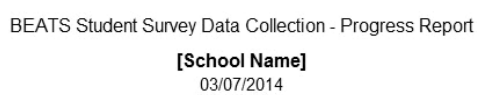

Table 1. Details of school visits for student survey data collection to date \begin{tabular}{lccccc}
\hline Testing date & $5 / 06 / 14$ & $9 / 06 / 14$ & $18 / 06 / 14$ & $26 / 06 / 14$ & Total \\
Day of the week & Thur & Mon & Wed & Thu & - \\
\hline Number of testing periods $(\mathrm{n})$ & 2 & 2 & 2 & 1 & 7 \\
Total students tested $(\mathrm{n})$ & 52 & 41 & 38 & 26 & 157 \\
Students surveyed per period $(\mathrm{n})$ & 26 & 20.5 & 19 & 26 & - \\
Students consented to wear activity meters $(\mathrm{n})$ & 24 & 13 & 13 & 15 & 65 \\
Research staff present $(\mathrm{n})$ & 4 & 4 & 7 & 6 & - \\
\hline
\end{tabular}

Table 2. Students surveyed to date

\begin{tabular}{lcccccc}
\hline & Year 9 & Year 10 & Year 11 & Year 12 & Year 13 & Total \\
\hline Students $(\mathrm{n})$ & 52 & 45 & 26 & 15 & 19 & 157 \\
o Boys & 26 & 23 & 13 & 7 & 15 & 84 \\
0 Girls & 26 & 22 & 13 & 8 & 4 & 73 \\
\hline
\end{tabular}

Figure 5. Example of a progress report prepared for each participating school during the BEATS Student Survey data collection

each school informed about recruitment and data collection within their school (Figure 5). These reports were well received by the schools and facilitated recruitment of students within each school.

Managing a Multidisciplinary Research Project. Management and coordination of the BEATS Study included monthly meetings of the BEATS research team, regular progress reports, preparing an annual report for stakeholders, sharing information and resources using Dropbox, and clarifying contributions and expectations.

\section{Dissemination}

Timely dissemination of the study results to the community was one of the key elements emphasized during the planning of the BEATS Study. From our previous experiences of working with the local schools and the city council, our research team made an extra effort to disseminate preliminary findings to the local community in a timely fashion as the results become available rather than waiting for two to four years before the results are published in the scientific journals. For example, data collection for the BEATS Student Survey was completed in nine schools between February and September 2014. Preliminary findings from these data were presented to the stakeholders, academic community and general public at the BEATS Study Symposium in November 2014. Our research team aims to submit detailed reports with the results of the student survey for each participating school within one year from completion of data collection. Specific reports for stakeholders such as the report on reasons for choosing a secondary school for Dunedin Secondary Schools' Partnership and reports on perceptions of cycle skills training and bike library for Dunedin City Council are also aimed to be finalized within six months from data collection. Further dissemination of the research findings will continue through scientific publications, public lectures, and seminars.

\section{Selected Preliminary Findings from the BEATS Study}

To illustrate some of the findings from the BEATS Student Survey, we present here preliminary results on transport to school habits and preferences and variations of active transport versus motorised transport use by secondary school students in Dunedin, New Zealand.

In 2014, 1,272 adolescents (age: $15.3 \pm 1.4$ years; $46.6 \%$ boys) from nine secondary schools in Dunedin, New Zealand, completed an online survey. The participants excluded from the analysis were 62 adolescents with incomplete consents, 30 invalid surveys and 120 boarding students (boarding at school $(\mathrm{n}=104)$ or privately $(\mathrm{n}=16)$ ). 
Therefore, a total of 1,160 adolescents were included in the analysis. We determined invalid surveys by observing the students as they completed the questionnaire online during school time and in a school room. We regard this procedure as essential to establishing the integrity of the questionnaire responses.

Participants completed an anonymous online questionnaire (30 to 40 minutes) during class time. The survey included questions about age, gender, ethnicity, school, and home address. Home address data were used to calculate distance to school using Google Maps and to determine neighbourhood area deprivation score as a surrogate for students' socioeconomic status (Salmond, Crampton, King, \& Waldegrave, 2006). Transport to school habits were assessed using a question «How do you usually travel to school?» for different transport modes with response categories «never», «rarely», «sometimes», «most of the time» and «all of the time». Based on the mode(s) of transport to school that students reported using «most of the time» and/or «all of the time», students were classified as using motorised transport (car or bus), active transport (walking, cycling or riding a scooter to school), or a combined motorized and active modes transport (for example, a combination of walking and bus, car and walk) on a single journey to school. Adolescents were also asked if they like the way they travelled to school. If they reported not liking the way they travelled to school, adolescents were asked to indicate preferred alternative modes of transport to school. Data presented here were analysed using descriptive statistics, including cross-tabulation and the associated chi-square test.

The sample for this study consisted of 1,160 adolescents (mean age: $15.3 \pm 1.4$ years; $45.1 \%$ boys; $74.3 \%$ New Zealand European) Overall, the most common modes of transport to school were being driven by others (45.8\%) and walking (33.0\%) followed by school bus (15.8\%), public bus (5.5\%), driving (4.2\%), cycling (1.9\%) and other modes (2.3\%). On average, $66.0 \%$ of students used motorized transport to school, $29.3 \%$ used ATS and 4.6\% used a combination of motorized transport and ATS. A large variation in the use of ATS was observed among nine participating schools (Figure 6; $\chi^{2} \mathrm{p}<0.001$ ). The vast majority of students (88.3\%) liked the way they travelled to school (87.6\% of students using motorized transport, $90.7 \%$ using ATS and 83.7\% of students using combined motorized transport and ATS; $\mathrm{p}=0.215$ ). Among the students who did not like the way they travelled to school $(\mathrm{n}=124(11.7 \%))$, most students preferred to be driven to school $(n=78)$ or to drive to school $(n=52)$ with less preference for walking $(\mathrm{n}=32)$ or cycling to school ( $\mathrm{n}=21)$, taking school bus $(\mathrm{n}=17)$ or public transport ( $\mathrm{n}=11)$ or using other modes of transport to school (motor bike $(\mathrm{n}=25)$, motor scooter $(\mathrm{n}=18)$, skateboard $(\mathrm{n}=10)$ and scooter $(\mathrm{n}=11))$.

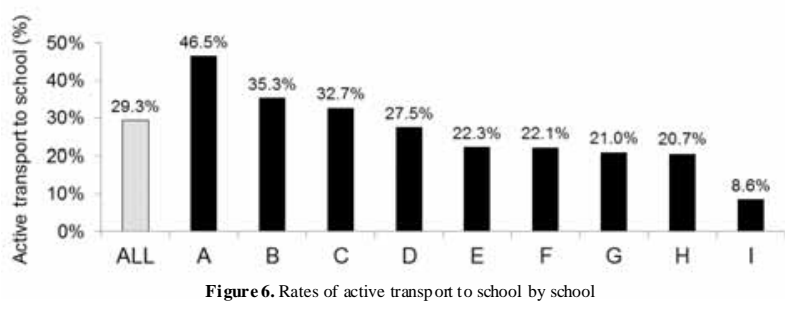

These preliminary findings from the BEATS Student Survey indicate that on average one third of adolescents in Dunedin, New Zealand regularly use ATS, however ATS rates vary greatly between schools. In addition, most students like the way they travel to school, which suggests that future public health interventions aimed at increasing ATS rates should address social norms and perceptions of different modes of transport to school. Substantial variation in ATS rates by school suggest that school-specific factors such as socio-demographic characteristics of students, school culture and norms, school policies such as school catchment area, school location, as well as infrastructure and perceptions of the built environment around the school need to be considered when designing the interventions for promoting ATS in adolescents in a particular school. Therefore future interventions for encouraging ATS in adolescents need to be comprehensive and address modifiable barriers at one or more levels of the ecological system. In short, one size does not fit all when considering ATS interventions.

The variation in ATS rates among Dunedin schools may at least in part be related to the school location and the surrounding environment. Recent studies identified a number of environmental factors associated with ATS including distance to school (Babey et al., 2009; Larsen et al., 2009; McDonald, 2008), route to school (Panter et al., 2010), topography (Timperio et al., 2006), street connectivity (Timperio et al., 2006), land usemix (Larsen etal., 2009; Panter etal., 2010), residential density (Larsen et al., 2009), busy intersections (Timperio et al., 2006), intersection density (Timperio et al., 2006), and neighbourhood walkability (Kerr et al., 2006). In addition, previous studies identified safety concerns, particularly parental concerns for road and neighbourhood safety, as important barriers to ATS in children (Chillon et al., 2014; Kerr et al., 2006; McMillan, 2005; Timperio et al., 2006) and adolescents (Kerr et al., 2006; Mandic et al., 2014). Future data analyses from the BEATS Study will examine environmental influences such as infrastructure, traffic and pedestrian safety perceptions and topography around individual schools. Based on the extensive evidence from the literature, future interventions to encourage ATS in adolescents should address modifiable characteristics of the built environment and, where justifiable, attempt to reduce parental and students' safety concerns associated with ATS.

The finding that most students actually like the way they travel to school presents another large barrier for school-based interventions to promote ATS. Therefore, future ATS interventions need to lead to a wider cultural change with respect to the perceptions of ATS and social norms related to transport to school in adolescents. These preliminary findings illustrate how the BEATS Study will provide valuable and unique information for schools, city councils, transport agencies and land planners and will help inform infrastructure developments, education campaigns, school policy development and city policy development in the local context.

The strengths of the illustrative results presented in this article include a representative sample of adolescents from $75 \%$ of secondary schools across one city and data collection across three seasons (fall, winter and spring). The limitations of the data presented here include a cross-sectional study design, data collection in one city, and lack of analysis of personal, social, environmental and policy factors that influence variability of ATS rates by school. Future analyses of the BEATS Study data will use multivariate analyses to examine multiple correlates of ATS simultaneously across all levels of the ecological model.

\section{Conclusions}

The BEATS Study is examining the effects of personal, social, environmental and policy factors on ATS in New Zealand adolescents. Preliminary findings from the BEATS Student Survey presented in this report suggest that on average one third of adolescents in Dunedin, New Zealand regularly use ATS but ATS rates vary greatly by school and most of students like the way they travel to school. Therefore, schoolspecific factors and student preferences need to be taken into account when designing the interventions for promoting ATS in adolescents in a particular school. These findings have significant implications for future public health interventions aimed at increasing ATS rates in adolescents.

\section{Acknowledgments}

The BEATS Study is a collaboration between Dunedin Secondary Schools' Partnership, Dunedin City Council and University of Otago. We would like to acknowledge our international collaborators (Prof John Spence and Assoc Prof Enrique García Bengoechea), the members of the BEATS Study Advisory Board (Mr Andrew Lonie, Mrs Ruth 
Zeinert, Dr Tara Duncan, Dr Susan Sandretto, Dr Janet Stephenson), research personnel (research assistants, students and volunteers), and all participating schools and students.

\section{Funding}

This study has been funded by Health Research Council of New Zealand, National Heart Foundation of New Zealand, Lottery Health Research Grant (New Zealand), University of Otago Research Grant, Dunedin City Council and internal grants from the School of Physical Education, Sport and Exercise Sciences, University of Otago.

\section{References}

Babey, S. H., Hastert, T. A., Huang, W., \& Brown, E. R. (2009). Sociodemographic, family, and environmental factors associated with active commuting to school among US adolescents. J Public Health Policy, 30 Suppl 1, S203-220.

Bringolf-Isler, B., Grize, L., Mader, U., Ruch, N., Sennhauser, F. H., \& Braun-Fahrlander, C. (2008). Personal and environmental factors associated with active commuting to school in Switzerland. Prev Med, 46(1), 67-73.

Carver, A. (2010). Are children and adolescents less active if parents restrict their physical activity and active transport due to perceived risk? Social science \& medicine (1982), 70(11), 1799-1805.

Chillon, P., Hales, D., Vaughn, A., Gizlice, Z., Ni, A., \& Ward, D. S. (2014). A cross-sectional study of demographic, environmental and parental barriers to active school travel among children in the United States. International Journal of Behavioral Nutrition and Physical Activity, 11, 61.

Chillón, P., Martínez-Gómez, D., Ortega, F. B., Pérez-López, I. J., Díaz, L. E., Veses, A. M., . . . Delgado-Fernández, M. (2012). SixYear Trend in Active Commuting to School in Spanish Adolescents. International Journal of Behavioral Medicine, 1-9.

Faulkner, G. E. J., Buliung, R. N., Flora, P. K., \& Fusco, C. (2009). Active school transport, physical activity levels and body weight of children and youth: A systematic review. Prev Med, 48(1), 3-8.

Guthold, R., Cowan, M. J., Autenrieth, C. S., Kann, L., \& Riley, L. M. (2010). Physical activity and sedentary behavior among schoolchildren: a 34-country comparison. J Pediatr, 157(1), 43-49 e41.

Howe, A. S., Mandic, S., Parnell, W. R., \& Skidmore, P. M. (2013). Attitudes to food differ between adolescent dieters and non-dieters from Otago, New Zealand, but overall food intake does not. Public Health Nutr, 16(1), 36-45.

Kerr, J., Rosenberg, D., Sallis, J. F., Saelens, B. E., Frank, L. D., \& Conway, T. L. (2006). Active commuting to school: Associations with environment and parental concerns. Med Sci Sports Exerc, 38(4), 787-794.
Larsen, K., Gilliland, J., Hess, P., Tucker, P., Irwin, J., \& He, M. (2009). The influence of the physical environment and sociodemographic characteristics on children's mode of travel to and from school. Am J Public Health, 99(3), 520-526.

Mandic, S., García Bengoechea, E., Stevens, E., Leon de la Barra, S., \& Skidmore, P. (2012). Getting kids active by participating in sport and doing it more often: focusing on what matters. International Journal of Behavioral Nutrition and Physical Activity, 9, 86.

Mandic, S., Leon de la Barra, S., Garcia Bengoechea, E., Stevens, E., Flaherty, C., Moore, A., . . S Skidmore, P. (2014). Personal, social and environmental correlates of active transport to school among adolescents in Otago, New Zealand. J Sci Med Sport.

McDonald, N. C. (2007). Active transportation to school: trends among U.S. schoolchildren, 1969-2001. Am J Prev Med, 32(6), 509-516.

McDonald, N. C. (2008). Critical factors for active transportation to school among low-income and minority students. Evidence from the 2001 National Household Travel Survey. Am J Prev Med, 34(4), 341-344.

McMillan, T. E. (2005). Urban Form and a Child's Trip to School: The Current Literature and a Framework for Future Research. Journal of planning literature, 19(4), 440-456.

Mendoza, J. A., Watson, K., Nguyen, N., Cerin, E., Baranowski, T., \& Nicklas, T.A. (2011). Active commuting to school and association with physical activity and adiposity among US youth. J Phys Act Health, 8(4), 488-495.

Ministry of Transport. (2011). New Zealand Household Travel Survey 2007-2010.

Moore, A., Middlemiss, M., Hodge, C., Skidmore, P., \& Mandic, S. (2013). Spatial aspects of a comparative study of active transport to school and motorized transport (conference paper). Paper presented at the NZIS and SIRC NZ, Dunedin, New Zealand.

Pabayo, R., Gauvin, L., \& Barnett, T. A. (2011). Longitudinal changes in active transportation to school in Canadian youth aged 6 through 16 years. Pediatrics, $128(2)$, e404-413.

Panter, J. R., Jones, A. P., Van Sluijs, E. M., \& Griffin, S. J. (2010). Neighborhood, route, and school environments and children's active commuting. Am J Prev Med, 38(3), 268-278.

Sallis, J. F., Cervero, R. B., Ascher, W., Henderson, K. A., Kraft, M. K., \& Kerr, J. (2006). An ecological approach to creating active living communities. Annu Rev Public Health, 27, 297-322.

Salmond, C., Crampton, P., King, P., \& Waldegrave, C. (2006). NZiDep: a New Zealand index of socioeconomic deprivation for individuals. Soc Sci Med, 62(6), 1474-1485.

The World Bank. (2014). Motor vehicles (per 1,000 people). Retrieved 18 Dec 2014, 2014, from http://data.worldbank.org/indicator/ IS.VEH.NVEH.P3

Timperio, A., Ball, K., Salmon, J., Roberts, R., Giles-Corti, B., Simmons, D., . . . Crawford, D. (2006). Personal, family, social, and environmental correlates of active commuting to school. Am JPrev Med, 30(1), 45-51.

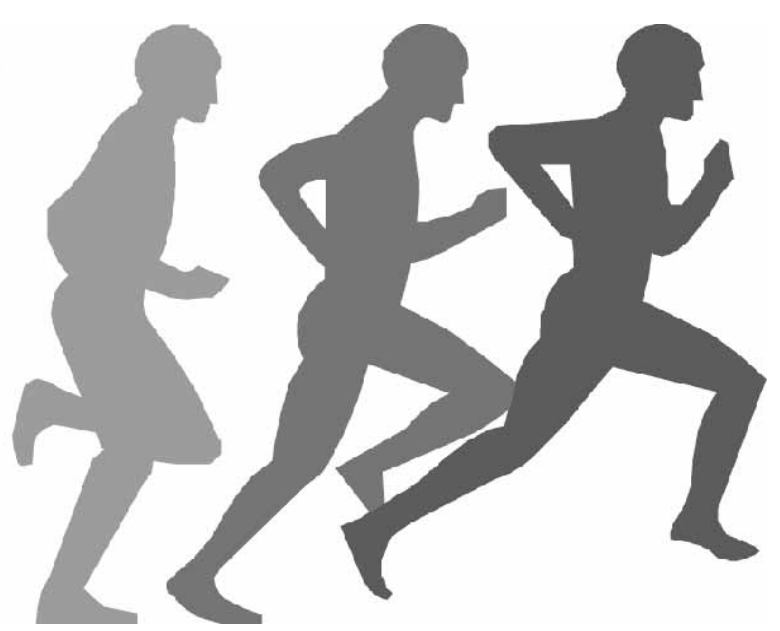

